\title{
FLEXURAL CAPACITY OF HIGH PERFORMANCE SELF COMPACTING RC BEAMS UNDER DIRECT FIRE
}

\author{
A. A. M.Badawy ${ }^{1}$, M. H. Seleem ${ }^{1}$, A. M. El shihy ${ }^{2}$ and A. E. K. Gabal ${ }^{1}$ \\ ${ }^{1}$ Materials Engineering Dept., Faculty of Engineering, Zagazig, Egypt \\ ${ }^{2}$ Structural Engineering Dept., Faculty of Engineering, Zagazig, Egypt
}

\begin{abstract}
This work analyses the structural behavior of high performance self compacting reinforced concrete (RC) beams under direct fire. Concrete strength of about $130 \mathrm{MPa}$ was investigated. Six reinforced concrete beams represents three types of concrete mixes were investigated. The first mix was high performance self compacting concrete (HPSCC) without fibers. The second mix was HPSCC with the presence of steel fibers (SF). The third mix was HPSCC with hybrid fibers, SF and two types of polypropylene fibers (micro-polypropylene and polyolefin). Three beams representing the three mixes were tested at room temperature without exposure to fire. The other corresponding three beams were tested under direct fire, while they were loaded at $45 \%$ from the fracture load of the corresponding three beams tested at room temperature to failure. All beams were tested under 3-points bending. Experimental results clearly indicated the superior effect of adding hybrid fibers to such concrete in reducing explosive spalling and increasing flexural capacity of RC beams when exposed to direct fire.

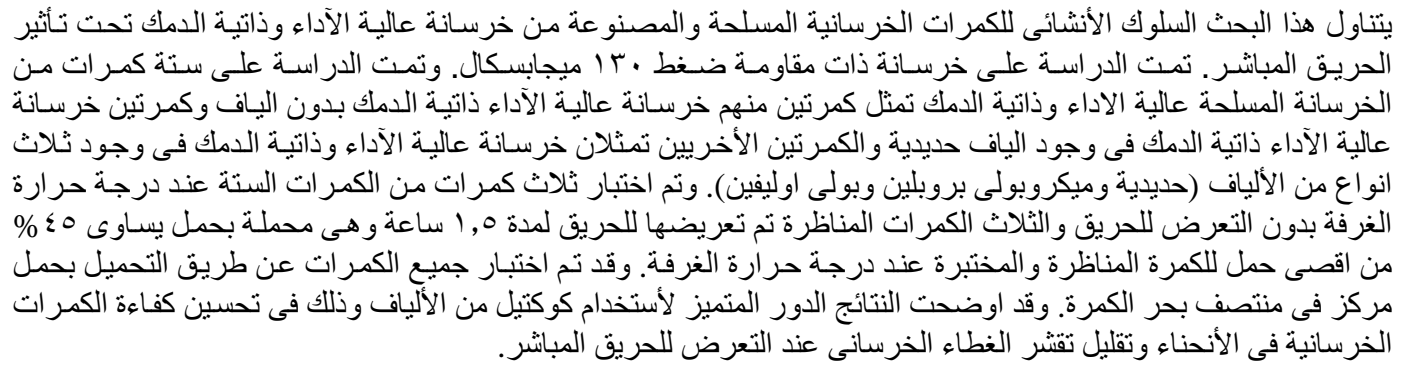

Keywords: High performance concrete; Self compacting concrete; RC beams; Fire; Hybrid fibers; Steel fibers1

\section{INTRODUCTION}

Reinforced concrete beams function as critical load bearing structural members in a building, and hence the provision of appropriate fire resistance is one of the major design requirements in buildings. The basis for this requirement can be attributed to the fact that when fire suppression and control systems fail, structural integrity is the last line of defense. Fire impacts reinforced concrete members by raising the temperature of the concrete mass. This rise in temperature dramatically reduces the mechanical properties of concrete and steel. Moreover, fire temperatures induce new strains, thermal, and transient creep [1]. They might also result in explosive spalling of surface pieces of concrete members [2]. In previous studies, considerable evidence has emerged which shows that spalling of concrete in accidental fires causes severe damage to concrete members [3-5], especially for high-strength concrete (HSC) and normal strength concrete (NSC) with higher moisture content. In most cases spalling seems to be due to a combination of pore pressure generated by boiling of the free water content, and thermal stresses due to extreme temperature gradients. It can be affected by a number of influences such as temperature gradient, internal thermal micro- cracking, cracking around reinforcement bars and strength loss due to chemical transitions [6,7]. HSC is believed to be more susceptible to this pore pressure build up because of its low permeability compared to NSC. The extremely high water vapor pressure, generated during exposure to fire, cannot escape due to the high 
density of HSC and this pressure can reach the saturation vapor pressure [8]. At $300{ }^{\circ} \mathrm{C}$, the pore pressure often reaches about $8 \mathrm{MPa}$. Such internal pressures are too high to be resisted by HSC having a tensile strength of about $5 \mathrm{MPa}$ [9].

High-performance concrete (HPC) has become an attractive option to NSC. HPC is a specialized concrete designed to provide several benefits in the construction of concrete structures. HPC offers high strength, better durability properties, and good construction. High strength is one of the important attributes of HPC. The HPC offers significant economic and architectural advantages over NSC in the correct situations, and is suited well for constructions that require high durability. Highperformance concretes having strength in excess of $70 \mathrm{MPa}$ are often used in a wide range of applications. Although HPC has been shown to have a number of advantages when used in concrete structures, it suffers from one major weakness: higher brittleness. When exposed to high temperatures, HPC exhibits more serious degradation than normal concretes do, such as spalling and cracking [10]. Fibers have extensively been used to improve the ductility of concrete. Recently, it has been found that a number of fibers can also improve the residual properties of concrete after exposure to elevated temperatures. Polypropylene (PP) fibers and steel fibers (SF) have been used to reduce spalling and cracking and to enhance the residual strength [11-14]. The primary objective of the present work is to investigate the flexural behavior of RC beams fabricated from HPSCC under direct fire, highlighting the effect of incorporating single or hybrid fibers to the concrete mix.

\section{EXPERIMENTAL PROGRAM}

All materials used in the present work are locally available materials except SF and PP. Type I ordinary Portland cement was used. Quartz fine sand with maximum nominal size of $0.6 \mathrm{~mm}$ was used as aggregate. High ratio of silica fume was used to produce HPSCC [15]. Silica flour is a quartz powder from pure sand. This silica flower was ground to a very fine powder with a diameter ranging from 0.125 to $1.00 \mu \mathrm{m}$ and used as micro filler to optimize the packing density of the powder mixture. The length and aspect ratio were $60 \mathrm{~mm}$ and 67 for the SF, 12 $\mathrm{mm}$ and 667 for the micro-PP and $25 \mathrm{~mm}$ and 65.8 for the polyolefin (PO) fibers. The used Superplasticizer was Glenium110M from BASF Company, which complies with ASTM C494 Types B. The water used in this study was clean potable water free from impurities and organic matters. These materials were used to make three HPSCC mixes. The first mix, Mix I, was without fibers, while the second mix, Mix II, was with SF and the third mix, Mix III, was with the three types of fibers (micro-PP, PO and SF).
The materials required to produce one cubic meter from each mix are given in Table 1 . Slump flow test was carried out according to ASTM C 1611 to measure the fresh properties of the three HPSCC mixes and the results are given in Table 2. The average compressive strength of the three mixes measured was $130 \mathrm{MPa}$.

Table 1, Mix proportions for producing one cubic meter

\begin{tabular}{|c|c|c|c|c|}
\hline \multirow{2}{*}{\multicolumn{2}{|c|}{ Materials }} & \multicolumn{3}{|c|}{ Quantities } \\
\hline & & Mix I & Mix II & MixIII \\
\hline \multicolumn{2}{|c|}{ Cement (kg) } & 700 & 700 & 700 \\
\hline \multicolumn{2}{|c|}{ Silica Fume (kg) } & 203 & 203 & 203 \\
\hline \multicolumn{2}{|c|}{ Sand (kg) } & 1080 & 1080 & 1080 \\
\hline \multirow{2}{*}{$\begin{array}{l}\text { Silica } \\
\text { Flour } \\
\text { (Kg) }\end{array}$} & $20 \mu \mathrm{m}$ & 90 & 90 & 90 \\
\hline & $75 \mu \mathrm{m}$ & 90 & 90 & 90 \\
\hline \multicolumn{2}{|c|}{$\begin{array}{l}\text { Super Plasticizer } \\
\text { (lit) }\end{array}$} & 38 & 38 & 38 \\
\hline \multicolumn{2}{|c|}{ Water (lit) } & 161 & 161 & 161 \\
\hline \multicolumn{2}{|c|}{$\begin{array}{l}\text { Dramix Steel Fiber } \\
\text { RC-65/60BN }\end{array}$} & - & $1.3 \%$ & $1.3 \%$ \\
\hline \multicolumn{2}{|c|}{$\begin{array}{l}\text { Micro-polypropylene } \\
\text { fiber }\end{array}$} & - & - & $0.13 \%$ \\
\hline \multicolumn{2}{|c|}{ Polyolefin } & - & - & $0.6 \%$ \\
\hline \multicolumn{2}{|c|}{$\begin{array}{l}\text { Silica fume/Cement } \\
\text { (S/C) }\end{array}$} & \multicolumn{3}{|c|}{$29 \%$} \\
\hline \multicolumn{2}{|c|}{ Water/Cement (w/c) } & \multicolumn{3}{|c|}{0.23} \\
\hline \multicolumn{2}{|c|}{ Water/Binder } & \multicolumn{3}{|c|}{$18 \%$} \\
\hline
\end{tabular}

Table 2, Slump flow values

\begin{tabular}{||c|c|c||}
\hline Mix & Slump flow diameter,mm & $\mathbf{T}_{\mathbf{5 0}}, \mathbf{s e c}$ \\
\hline Mix I & 770 & 3.9 \\
\hline Mix II & 760 & 4.0 \\
\hline Mix III & 725 & 4.3 \\
\hline
\end{tabular}

To investigate the flexural behavior of RC beams fabricated from the previous mixes, six beams were cast, two from each mix. The beam dimensions were $2500 \mathrm{~mm}$ total span, $2300 \mathrm{~mm}$ loaded span and $200 \times 200 \mathrm{~mm}$ cross section dimensions. Each beam was reinforced by $2 \Phi 14 \mathrm{~mm}$ as top reinforcement and $З \Phi 14 \mathrm{~mm}$ as bottom reinforcement. The stirrups were $5 \Phi 8 \mathrm{~mm} / \mathrm{m}$. The fabricated beams were demolded 24 hrs after casting and cured in water for 28 days. The beams were tested under 3-points bending 
configuration. One from the two was tested to failure at room temperature (RT), while the other was loaded by $45 \%$ from the RT fracture load, RTFL, of the corresponding beam and then subjected to direct fire under this sustained load. The beams fabricated from Mix I was denoted as BI, while those fabricated from Mix II and Mix III were denoted as BII and BIII respectively. A custom-built gas furnace was used to expose the RC beams to fire as shown in Fig. 1. The heating arrangement in the furnace is as according to ASTM E 119-00 specifications. The load was applied through pressure valve of 400 bar calibrated with handle jack by (NATIONAL INSTITUTE FOR STANDARD NIS). Deflection gauge with $35 \mathrm{~mm}$ travel fixed in the jack body was used to measure the deflection until $45 \%$ from the fracture load.

Steel rule with $0.5 \mathrm{~mm}$ accuracy was fixed in the steel frame beyond an indicator welded in the body of the jack to record the vertical movement of the jacks, beam deflection. High resolution digital camera 30X zooming and 3 hours recording time fixed on a surveying tripod was used to adjust the level. This camera was placed perpendicular to the steel rule and indictor. Three pipes were used to ensure that the fire is uniformly distributed with the same degree of temperature on the three sides of the beams through 30 nozzles for each pipe. Each pipe was connected to a gas cylinder with a safety regulator valve.

\section{RESULTS AND DISCUSSION}

\subsection{Load Deflection Behavior at Room Temperature}

Typical load-deflection curves for the three tested beams, BI, BII and BIII, tested at RT are shown in Fig. 2. These curves illustrate typical load-deflection behavior of RC beams. The recorded ultimate loads, Pult, for the three beams are 61, 74, $79 \mathrm{kN}$ respectively for BI, BII and BIII. The addition of SF to HPSCC, B II, leads to an increase by about $21 \%$ and $4 \%$ in the ultimate load and corresponding deflection, $\delta_{\text {ult }}$, compared to BI as shown in Fig. 3. These ratios increase to $30 \%$ and $12 \%$ when using hybrid fibers, BIII. These results show the effectiveness of hybrid fibers reinforcement in high strength concrete mixture in increasing the flexural strength and toughness of concrete by preventing the crack development.

\subsection{RC Beams under Direct Fire}

This study is focusing on the visual inspection of the RC beams exposed to fire. The time to reach failure is defined as the fire resistance for the beam.

A comparison of fire resistance of the three beams given in Table 4 indicates that spalling sounds are started inside the furnace after $15 \mathrm{~min}$ from the ignition of fire for beams BI at $690{ }^{\circ} \mathrm{C}$, while started after 20 and 28 min at $740{ }^{\circ} \mathrm{C}$ and $778{ }^{\circ} \mathrm{C}$ for BII and BIII respectively. Also, beam BI failed before reaching the target time of $1.5 \mathrm{hrs}$, while BII and BIII succeeded to stay without failure and to resist extra loads in the addition to the 45\% RTFL before fracture Examination of photos 1 and 2 clearly indicate the occurrence of sever spalling in beam BI. The spalling length was observed over most of the span of this beam. The spalled length reduced markedly to cover small portion at the beam midspan with the utilization of hybrid fibers as in the case of BIII.

Photo 3 shows a schematic for the spalled area in the HPSSC beams cross section, with and without fibers after fire exposure. It can be seen that the extent of spalling (ratio of area of spalled concrete to the original area of the concrete cross section) decreases with adding fibers. These observations can lead to the fact that once first spalling occurs, the pore pressure

will build up subsequently in the inner layers of concrete leading to further spalling in the beam. Improvement in spalling resistance was attained by adding steel and PP fibers to the HPSCC concrete mix. Further, spalling, which results in a decrease in the cross-section at later stages of fire exposure, contributed to lowering the fire resistance of the HPSCC beams. Referring to the results recorded for the deflection in RC beams given in Table 5 and Fig. 4, the following observations can be recorded: Beam BI failed before reaching the desired target test time of $1.5 \mathrm{hr}$. It failed after $76 \mathrm{~min}$ from the start of fire. The corresponding recorded deflection is 128 $\mathrm{mm}$. Beams BII and BIII succeeded to reach the target test time (1.5 hrs). After fire switch of, the total deflections caused by fire are found be 123 and 103 $\mathrm{mm}$ for BII and BIII respectively. In the addition to the existing load (45\% RTFL), extra loads are applied to beams BII and BIII until the hydraulic jack, could no longer maintain the load. These extra loads were 6.7 and $10.4 \mathrm{kN}$ respectively for BII and BIII.

These extra loads caused additional deflections in the two beams equal to $22 \mathrm{~mm}$ and $46 \mathrm{~mm}$ for BII and BIII respectively. The accumulative deflections corresponding to the ultimate loads recorded for the two beams became 145 and $149 \mathrm{~mm}$ for BII and BIII respectively. By comparing results found in Fig. 2 and Fig. 4, it can be observed that: at the moment the hydraulic jack, could no longer maintain the $45 \%$ pre-load ratio, the deflection recorded in beam BI after 76 minutes from fire exposure is $128 \mathrm{~mm}$. This deflection is equivalent to a deflection recorded at a load equals $99 \%$ of the RTFL for the beam tested without exposure to fire. This means that exposing beams without fibers, BI, for 76 minutes lost its ability to resist $45 \%$ RTFL or on other meaning exposing normal concrete beams without fibers for 
76 minutes generates stresses equivalent to those generates under $55 \%$ from RTFL. The deflection takes place in beam BII (with steel fibers), when loaded by $45 \%$ RTFL during exposure to fire for 90 minutes is equivalent to a deflection recorded at a load equals $95 \%$ of the RTFL for the corresponding beam tested without exposure to fire. Despite the beams attained these values of deflections, the presence of steel fibers make the beam able to carry extra load of $9 \%$ from RTFL before failure. Beam made with hybrid fibers, beam BIII, shows the same performance as BII with noticeable changes in values. Deflection after exposure to fire for 90 minutes decreased and became equivalent to a deflection recorded at a load equals $90 \%$ of the RTFL for the corresponding beam tested without exposure to fire. The ability of beam BIII to carry additional load after exposure to fire increased to $13 \%$.

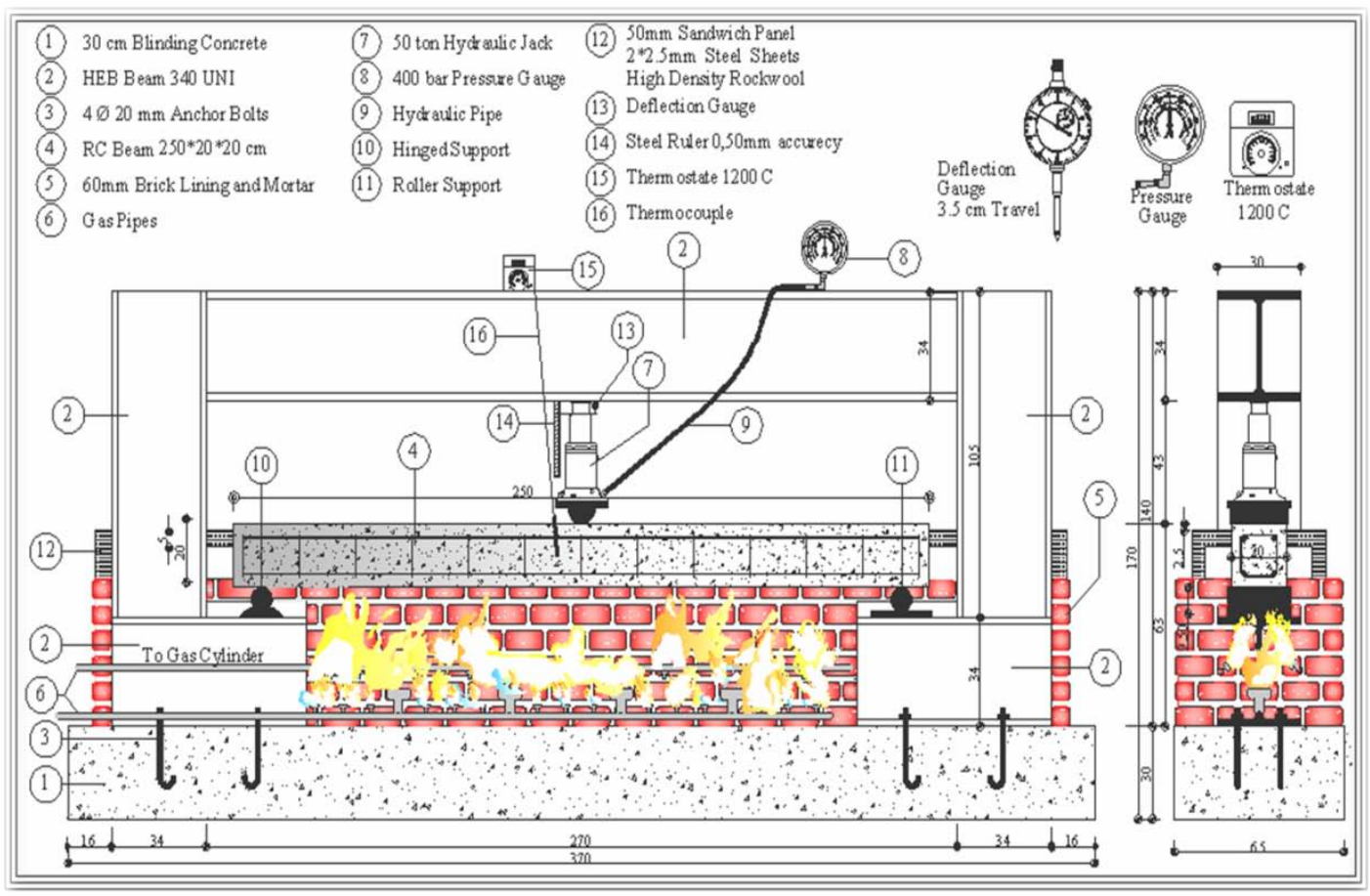

Fig. 1 Test setup for RC beams under gas furnace

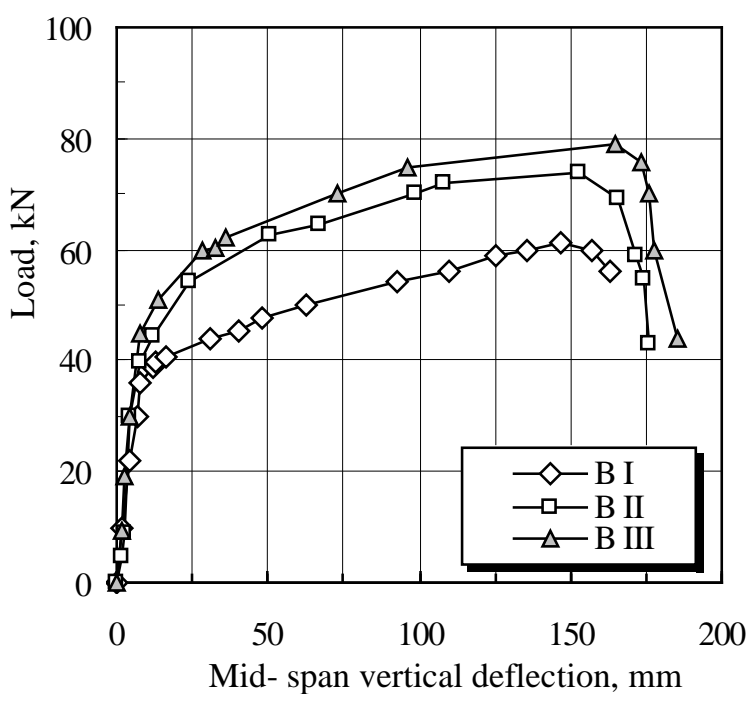

Fig. 2 Load-deflection curves RC beams tested at RT

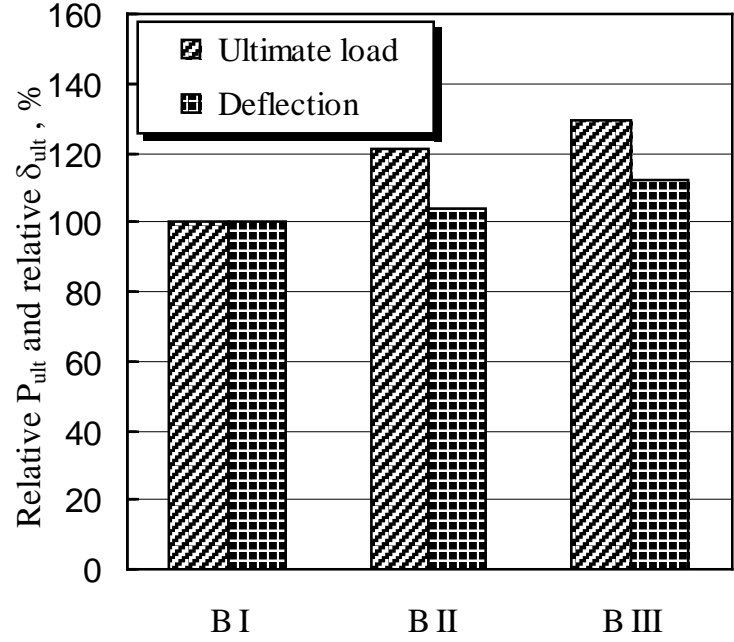

Fig. 3 Relative ultimate loads and corresponding relative deflection for RC beams at RT 
A. A. M. Badawy, M. H. Seleem, A. M. El shihy, A. E. K. Gabal, "Flexural Capacity of High Performance ..."

Table 4, Beams observation during exposing fire

\begin{tabular}{|c|c|c|c|c|c|c|}
\hline \multirow{3}{*}{ Beam } & \multirow{3}{*}{$45 \%$ RTFL, kN } & \multicolumn{4}{|c|}{ Sound of Spalling } & \multirow{3}{*}{$\begin{array}{l}\text { Test Discontinued } \\
\text { (failure time, min) }\end{array}$} \\
\hline & & \multicolumn{2}{|c|}{ Start } & \multicolumn{2}{|c|}{ End } & \\
\hline & & Time, min & Temp., ${ }^{\circ} \mathrm{C}$ & Time, min & Temp., ${ }^{\circ} \mathrm{C}$ & \\
\hline BI & 27.5 & 15 & 690 & 45 & 840 & 76 \\
\hline BII & 33.3 & 20 & 740 & 62 & 867 & 90 (not failed) \\
\hline BIII & 35.6 & 28 & 778 & 75 & 875 & 90 (not failed) \\
\hline
\end{tabular}

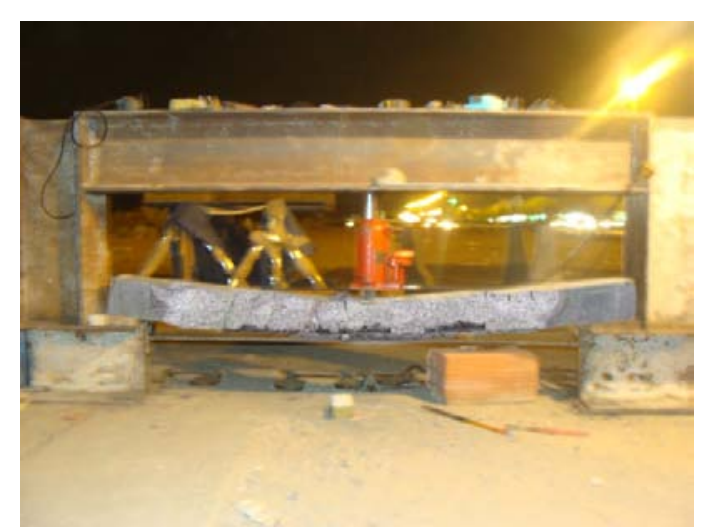

Photo 1 Normal HPSCC beam, BI, after exposing to fire

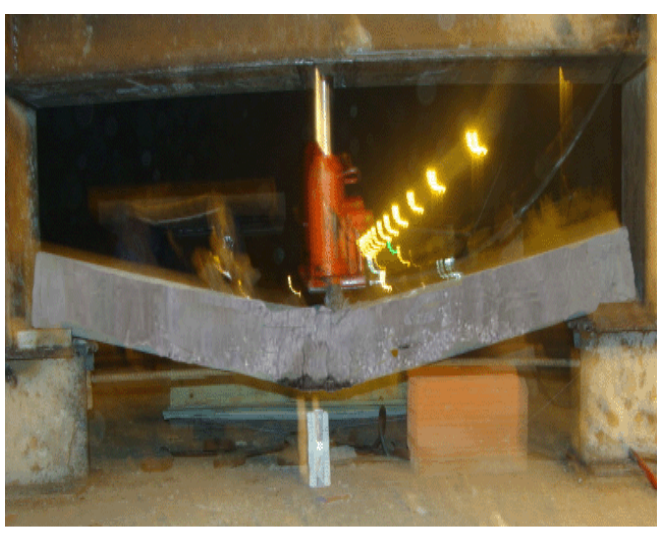

Photo 2 HPSCC beam, BIII, after exposing fire

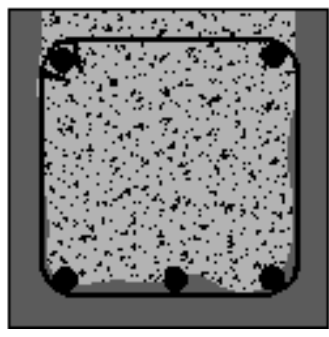

HPSCC cross section Without fibers

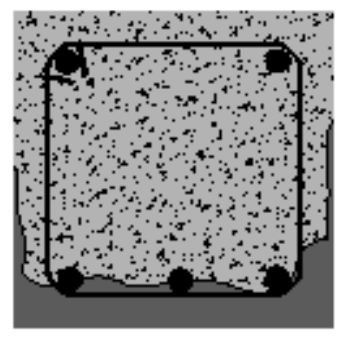

HPSCC cross section With fibers

Photo 3 Spalling in HPSCC beams cross section exposed to fire

Table 5, Beam deflections due to fire and extra loads

\begin{tabular}{|l|c|c|c|c|c||}
\hline \multirow{2}{*}{ Beam } & \multicolumn{2}{|c|}{ In fire } & \multicolumn{2}{c|}{ After fire } & $\begin{array}{c}\text { Total accumulative } \\
\text { deflection } \\
\text { corresponding to } \\
\text { ultimate load, mm }\end{array}$ \\
\cline { 2 - 5 } & Time, min & Deflection, mm & Extra load, kN & $\begin{array}{c}\text { Extra deflection } \\
\text { due to load, mm }\end{array}$ & 128 \\
\hline BI & 76 & 128 & \multicolumn{2}{|c|}{0} & 145 \\
\hline BII & 90 & 123 & 6.7 & 22 & 149 \\
\hline BIII & 90 & 103 & 10.4 & 46 & \multicolumn{2}{|c||}{} \\
\hline \hline
\end{tabular}




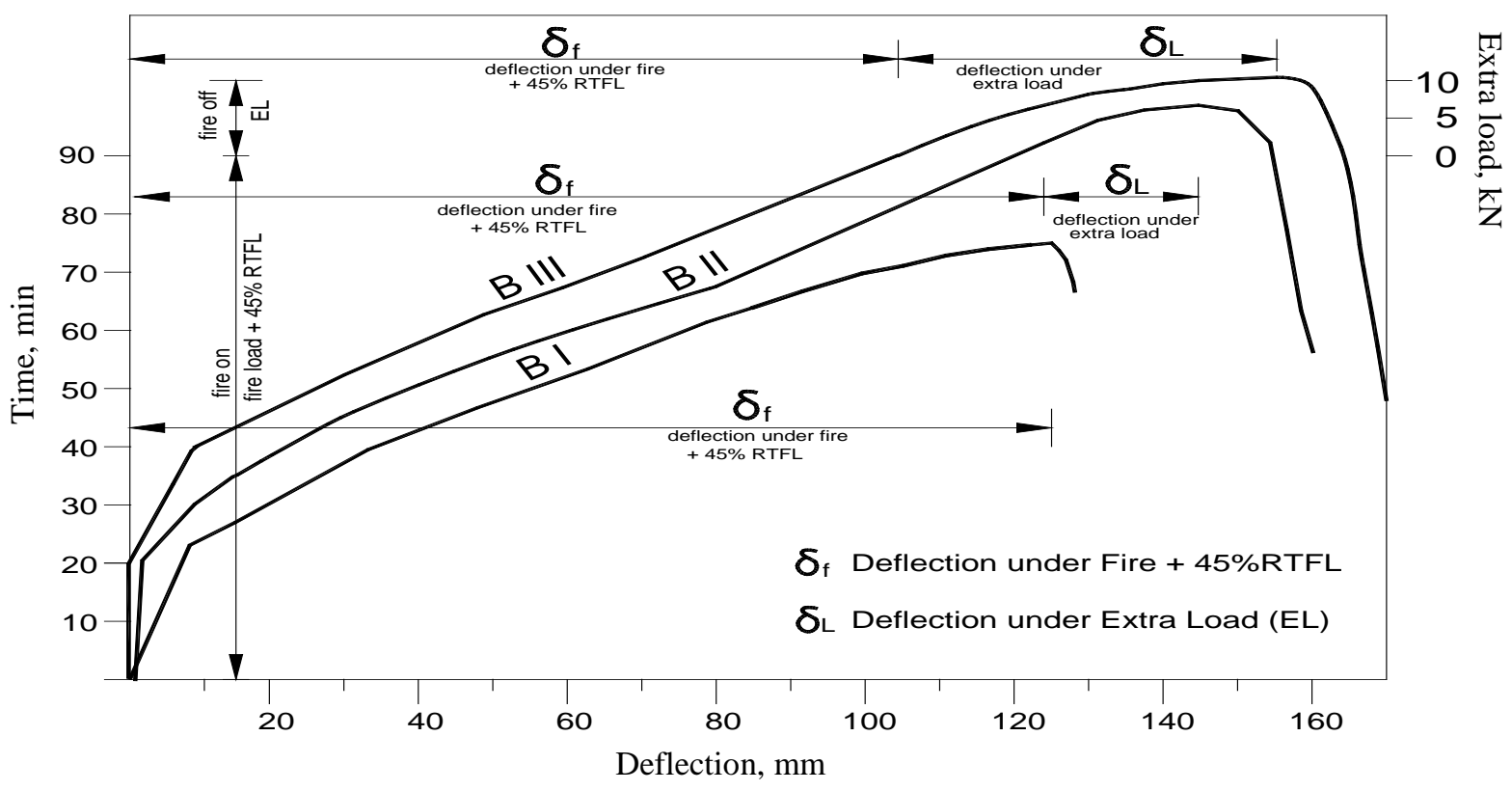

Fig. 4 Time-deflection curves for different RC beams

\section{CONCLUSIONS}

The results of the present experimental work support the following conclusions:

1. For RC beams tested at RT, the addition of steel fibers to HPSCC, caused an increase by about $21 \%$ and $4 \%$ in the ultimate load and corresponding deflection, while these ratios increased to $30 \%$ and $12 \%$ when using hybrid fibers from steel and polypropylene (micro-polypropylene and Polyolefin).

2. RC beams from HPSCC without fibers and load by about $45 \%$ from the fracture load of the corresponding beam test at RT failed to stay under direct fire for more than 76 min.

3. The addition of fibers, either single or hybrid, to HPSCC make the RC beams to stay under direct fire for $90 \mathrm{~min}$ without failure and cause a reduction in the measured deflection and increase the ability of these beams to sustain an extra load before failure.

4. Sever cover spalling occurred all over the span of HPSCC beams without fibers, while the addition of fibers reduced the spalling to a very limited length over the beam span. This can explain the unability of beam without fibers to maintain carrying the preload during exposure to fire and why this beam has the shortest life time among the other beams incorporating fibers.

\section{REFERENCES}

[1] M.A. Youssef and M. Moftah, "General stressstrain relationship for concrete at elevated temperatures”, Engineering Structures, Vol. 29, No.10, pp. 2618-2634, 2007.

[2] G.A. Khoury, "Effect of fire on concrete and concrete structures", Progress in Structural Engineering and Materials, Vol. 2, No.4, pp. 429-447, 2000.

[3] F. A. Ali, D. O’Connor and A. Abu-Tair, "Explosive spalling of high-strength concrete columns in fire", Magazine of Concrete Research, Vol. 53, No.3, pp. 197-204, 2001.

[4] C. Bailey, Holistic, "Behaviour of concrete buildings in fire", Proceedings of the ICE, Structures \& Buildings, Vol. 152, No.3, pp. 199-212, 2002.

[5] V. K. R. Kodur and M. Dwaikat, "Flexural Response of Reinforced Concrete Beams Exposed to fire”, Structural Concrete Journal, Vol. 9, No. 1, pp. 45-54, 2008.

[6] V.R.Kodur, "Guide lines for fire resistance design of high strength concrete columns", Journal of Fire Protection Engineering, Vol. 15, No.2, pp.93-106, 2005.

[7] Gai-FeiPeng , Wen-Wu Yang, Jie Zhao, YeFeng Liu, Song-HuaBian and Li-Hong Zhao, "Explosive Spalling and Residual Mechanical Properties of Fiber-Toughened High-Performance Concrete Subjected to High Temperatures”, Cement and Concrete Research, Vol. 36, pp. 723-727, 2006. 
[8] V.K.R. Kodura and L. Phan, "Critical factors governing the fire performance of high strength concrete systems”, Fire Safety Journal, Vol. 42, pp. 482-488, 2007.

[9] U. Diederichs, U. M. Jumppanen and U. Schneider, "High temperature properties and spalling behaviour of HSC ”, Proceedings of the Fourth Weimar Workshop on HPC, HAB Weimar, Germany, pp.219-235, 1995.

[10] C.S. Poon, S. Azhar,M. Anson and Y.L.Wong, "Performance of metakaolin concrete at high temperatures”, Cement Concrete Composite, Vol. 25, pp. 83- 89, 2003.

[11] A. Lau and M. Anson, "Effect of high temperatures on high performance steel fibre reinforced concrete”, Cement and Concrete Research Vol.36, pp. 1698-1707,2006.

[12] P. Kalifa, G. Chene and Ch. Galle, “ Hightemperature behavior of HPC with polypropylene fibers from spalling to microstructure", Cement and Concrete Research, Vol.31, pp. 1487-1499, 2001.

[13] Albert N. Noumowe, Rafat Siddique and G. Debicki, "Permeability of high- performance concrete subjected to elevated temperature $\left(600^{\circ} \mathrm{C}\right)$ ", Construction and Building Materials, Vol. 23, pp. 1855-1861, 2009.

[14] Takashi Horiguchi and Sofren Leo Suhaendi, "Recovery Behavior of Hybrid Fiber High Performance Strength Concrete After Fire Exposure", Application of Structural Fire Engineering, Prauge, Czech Republic, 19-20 Feb. 2009.

[15] Jianxin Ma and Jorg Dietz, "Ultra High Performance Self Compacting Concrete”, Institute for structural concrete, University Leipzig, LACER No. 7, pp.33-43, 2002. 